\title{
Obituaries
}

\section{Dr. John Anderson McConnell}

John Anderson McConnell, an active member of the Canadian Anaesthetists' Society, British Columbia Division, and a member of the Active Staff, Department of Anaesthesia, Burnaby General Hospital, passed away in Vancouver on September 23, 1982.

Jack McConnell was born in Moose Jaw, Saskatchewan, in 1925 and moved to Vancouver with his family at an early age. He received his $B A$ in 1946 from the University of British Columbia and his Mo degree in 1953 at the University of Western Ontario. Following internship, and a year of General Surgery Residency at the Vancouver General Hospital, he located in Duncan, B.C. for six years, as a General Practitioner. In 1961 he enrolled in the Residency Training program of the Department of Anaesthesia, Vancouver General Hospital and the University of British Columbia. Certified as a Specialist by the Royal College in 1964, he joined the staff of the Vancouver General Hospital and the teaching staff of U.B.C., where he used his special talents in the field of Paediatric and Cardiovascular anaesthesia. Ill-health forced his resignation from V.G.H. in 1976. Upon recovery in 1978, he joined the staff of the Bumaby General Hospital. Jack was a member of the Alpha Omega Honour Medical Society, the Canadian and B.C. Medical Associations, the B.C. and Canadian Anaesthetists' Societies.

Extremely well respected and liked by his medical associates and other hospital personnel, Jack will be greatly missed by all of us who knew him well. He is survived by his wife Wanda; son Sean, daughters Patricia and Alva and four grandchildren.

H.B.G.

\section{Dr. Malcolm Manus Marks}

Dr. Malcolm Marks died suddenly on October 24, 1982, aged 52 years. Malcolm was born in Liverpool, England, and subsequently moved to Salford. He graduated from the College of Physicians and Surgeons in Ireland in 1957, with a gold medal in surgery. He moved to New York, to undertake an internship in Elmira. In 1960, he relocated to Canada where he made his home. He entered general practice in Scarborough, then Mattawa and finally North Bay, where he was on the staff of the Civic and St. Joseph's hospitals from 1962 to 1969. In North Bay, Malcolm was an active participant in the affairs of the medical community and began his career in anaesthesia. This culminated in his decision to take formal anaesthesia training at the University of Toronto, which he commenced in 1970. He obtained the F.R.C.P.(C) in 1973, spent a few months at the Wellesley Hospital in Toronto and then went into anaesthesia practice in Farmington, Maine. However, he returned to the Wellesley hospital in 1975 where he was a senior staff anaesthetist and Assistant Professor of Anaesthesia at the University of Toronto.

Malcolm was a meticulous anaesthetist with special interest in equipment safety, respiratory physiology, and intensive care. He demanded the best for patients coming into his care and was especially concerned with the training of residents, teaching them to develop similar standards to his own. Departmental conferences would never be dull when Malcolm was present, to quiz the lecturers and the residents with his penctrating questions. He was a member of the Canadian Anaesthetists' Society, the Canadian Medical Association and the Academy of Medicine, Toronto.

His passing leaves a void which will be hard to fill and his special qualities in the operating room and intensive care unit will long be remembered by all 